\title{
PRODUÇÃO DE ABOBRINHA EM FUNÇÃO DA IDADE DAS MUDAS
}

\author{
Squash production as a function of seedling age \\ Ariane da Cunha Salata ${ }^{1}$, Andréa Reiko Oliveira Higuti ${ }^{2}$, \\ Amanda Regina Godoy ${ }^{2}$, Felipe Oliveira Magro ${ }^{3}$, Antonio Ismael Inácio Cardoso ${ }^{3}$
}

\begin{abstract}
RESUMO
A idade do transplante de mudas é um fator de grande importância, pois pode afetar a qualidade e a produtividade das plantas, se o volume da célula da bandeja não for ideal ao tempo de permanência da muda. Neste estudo, objetivou-se avaliar o efeito da idade das mudas na produção de abobrinha 'Sandy'. Os tratamentos consistiram em cinco idades de transplante das mudas (36, 32, 28, 24 e 20 dias após a semeadura). O delineamento experimental foi em blocos ao acaso, com seis repetições e cinco plantas por parcela. As semeaduras foram realizadas a cada quatro dias, em bandejas de poliestireno de 128 células, com o objetivo de transplantar muda com diferentes idades, na mesma data (17/08/2007). Foram avaliados, no dia do transplante, o número de folhas na muda, massa fresca e seca da parte aérea das mudas e, após o transplante, a produção total de frutos por planta (número e massa) e a produção de frutos comerciais por planta (número e massa). As mudas transplantadas com 32 dias após a semeadura apresentaram maior número de folhas e massa fresca da parte aérea, porém, a maior produção de frutos por planta é obtida com mudas transplantadas aos 27 dias após semeadura, o que corresponde às mudas com 3,2 folhas.
\end{abstract}

Termos para indexação: Cucurbita moschata, produção de mudas, bandeja.

\begin{abstract}
The seedling transplant age is an important factor, since it may affect the quality and yield of plants if the tray cell size is not ideal to the time that the seedlings remain in the tray. The objective of this study was to evaluate the effect of seedling age on the 'Sandy' zucchini production. Treatmeats consisted of five seedling transplanting ages (36, 32, 28, 24 and 20 days after sowing). The experimental design was randomized blocks, with six replicates and five plants per plot. Sowings were performed at each four days in polystyrene trays contaning 128 cells, in order to transplant seedlings with different ages at same day (08/17/2007). At the transplanting day, the number of seedling leaves, fresh and dry mass of the shoot, were avaluated and after transplanting, the fruit total yield per plant (number and mass) and commercial fruit yield per plant (number and mass). Seedlings with 32 days after sowing showed a higher number of leaves and shoot fresh mass, however, the highest fruit yield per plant is obtained with seedlings 27 days after sowing, which corresponds to seedlings with 3.2 leaves.
\end{abstract}

Index terms: Cucurbita moschata, seedling production, trays.

\section{(Recebido em 13 de janeiro de 2009 e aprovado em 27 de maio de 2010)}

\section{INTRODUÇÃo}

A abobrinha, pertencente à família das Cucurbitáceas, é originária de clima tropical. É uma planta anual em que ocorre o desenvolvimento simultâneo da parte vegetativa, da floração e da frutificação (Filgueira, 2003). Sua semeadura era realizada em covas ou em sulcos no local definitivo e, posteriormente, era feito o desbaste das plantas, o que aumentava o gasto com sementes. Atualmente, têm sido lançadas no mercado sementes de híbridos de abobrinhas que apresentam preço superior ao das cultivares de polinização aberta. Esse é um dos motivos pelos quais os produtores têm utilizado bandejas para produção de mudas, pois, nestas, coloca-se apenas uma semente por célula e, com o transplante, garante-se uma população uniforme e sem falhas. Ao contrário, na semeadura direta usualmente são colocadas duas ou três sementes por cova, para se tentar obter a mesma população de plantas. Portanto, a utilização de mudas permite melhor aproveitamento das sementes, facilita a realização dos tratos culturais iniciais (desbaste, capinas, irrigações e pulverizações), proporciona maior homogeneidade das plantas, diminuindo a possibilidade de falhas na área e garantindo a população desejada. Além disso, as bandejas atualmente utilizadas facilitam o transporte das mudas e possibilitam a reutilização das bandejas, além de causar menores danos às raízes por ocasião do transplante (Minami, 1995; Borne, 1999; Pereira \& Martinez, 1999).

\footnotetext{
'Universidade Estadual Paulista "Júlio de Mesquita Filho"/UNESP - Faculdade de Ciências Agronômicas/FCA - campus de Botucatu - Cx. P. 237 18603-970 - Botucatu, SP - ariane_salata@yahoo.com.br

2Universidade Estadual Paulista "Júlio de Mesquita Filho"/UNESP - Botucatu, SP

¿Universidade Estadual Paulista “Júlio de Mesquita Filho"/UNESP - Departamento de Produção Vegetal - Botucatu, SP
} 
De acordo com Minami (1995), a base da horticultura moderna é a produção de mudas de alta qualidade e uma muda bem formada dará origem a uma planta com alto potencial produtivo. Um fator importante, que pode afetar a qualidade e a produtividade das plantas, é a idade elevada das mudas no momento do transplante. Isso pode prejudicar o desenvolvimento das raízes e da parte aérea da planta, pois o volume da célula na bandeja pode não ser ideal para o tempo em que a muda lá permanece. Se a muda for mantida por um período muito longo na bandeja, ela poderá apresentar deficiência de nutrientes, podendo ocorrer até mesmo enovelamento das raízes. Isso geralmente acontece pelo atraso no transplante.

O tempo em que as mudas permanecem com seu sistema radicular restringido deve ser o mínimo possível (Pereira \& Martinez, 1999). Para as cucurbitáceas é recomendado que se transplantem as mudas com três semanas (Borne, 1999), pois são plantas que possuem desenvolvimento rápido. Já, Weston (1988), ao estudar a idade das mudas $(30,40,50$ e 60 dias após a semeadura), em pimentão, verificou que as mudas com 60 dias apresentaram maior precocidade, mas não houve diferença na produtividade. Entretanto, não foi observada a influência da idade da muda na precocidade em tomate (Leskovar et al., 1991), abobrinha (NeSmith, 1993) e melancia (Vavrina et al., 1993). Seabra Júnior et al. (2004) observaram redução na produção de pepino com a utilização de mudas com mais de 19 dias.

Segundo Belfort \& Gomes (2000), o insucesso de muitos empreendedores tem sido atribuído a não observação do momento adequado para o transplante. As mudas com sistema radicular restringido, quando transplantadas para o campo, são frequentemente incapazes de compensar a evapotranspiração, mesmo se bem irrigadas após o transplante (Pereira \& Martinez, 1999).

Para produtores de mudas, ocorre a tendência de se comercializarem mudas mais novas, para reduzir o tempo destas no viveiro de produção. Já, os produtores que irão cultivar estas mudas, preferem-nas mais desenvolvidas. Provavelmente, essa preferência está relacionada com a facilidade de transplante, pois estas apresentam um sistema radicular compacto, estruturado com um torrão que não se quebra no momento da retirada das bandejas (Seabra Júnior et al., 2004).

Com base no exposto, foi estabelecida a hipótese de que há um período máximo de permanência das mudas nas bandejas acima do qual podem ocorrer prejuízos no desenvolvimento das plantas e, consequentemente, na produção da cultura. Dessa forma, com esta pesquisa, objetivou-se avaliar o efeito da idade de transplante sobre o desenvolvimento das mudas e a produção da abobrinha e, assim, determinar o estágio fenológico ideal para o transplante.

\section{MATERIAL E MÉTODOS}

O experimento foi conduzido na Fazenda Experimental São Manuel, localizada no município de São Manuel-SP, pertencente à Faculdade de Ciências Agronômicas da UNESP, campus de Botucatu, Estado de São Paulo. Sua localização geográfica é definida pelas coordenadas 22\%46' de Latitude Sul e 48³4' de Longitude Oeste de Greenwich, com altitude média de $740 \mathrm{~m}$.

O clima predominante no município de São Manuel-SP, segundo a classificação de Köppen, é tipo $\mathrm{Cfa}$, temperado quente (mesotérmico) úmido e a temperatura média do mês mais quente é superior a $22^{\circ} \mathrm{C}$ (Cunha \& Martins, 2008).

O solo da área experimental é tipicamente um Latossolo Vermelho Distrófico (Empresa Brasileira de Pesquisa Agropecuária - Embrapa, 1999), com os seguintes resultados obtidos na análise química: $\mathrm{pH}\left(\mathrm{CaCl}_{2}\right)=5,4$; Presina $=64 \mathrm{mg} \mathrm{dm}^{-3}$; matéria orgânica $=14 \mathrm{~g} \mathrm{dm}^{-3} ; \mathrm{V} \%=60$; $\mathrm{H}+\mathrm{Al}=22 \mathrm{mmol} \mathrm{dm}^{-3} ; \mathrm{K}=3,2 \mathrm{mmol} \mathrm{dm}^{-3} ; \mathrm{Ca}=24 \mathrm{mmol}$ $\mathrm{dm}^{-3} ; \mathrm{Mg}=8 \mathrm{mmol}_{\mathrm{c}} \mathrm{dm}^{-3} ; \mathrm{SB}=34 \mathrm{mmol}_{\mathrm{c}} \mathrm{dm}^{-3}$ e CTC $=57$ $\mathrm{mmol}_{\mathrm{c}} \mathrm{dm}^{-3}$.

O delineamento experimental utilizado foi o de blocos ao acaso, com cinco tratamentos e seis repetições. Os tratamentos foram constituídos por diferentes idades de transplante das mudas $(36,32,28,24$ e 20 dias após a semeadura).

Para a produção das mudas, foram utilizadas sementes do híbrido Sandy, semeadas em bandejas de poliestireno de 128 células (células com altura de $6,2 \mathrm{~cm}$, largura $3,5 \mathrm{~cm}$ e volume de $34,6 \mathrm{~cm}^{3}$ ), preenchidas com substrato comercial (Plantmax ${ }^{\circledR}$ ), sendo depositada uma semente por célula. As semeaduras foram realizadas a cada quatro dias, a partir de 12 de julho de 2007, com o objetivo de transplantar mudas com diferentes idades na mesma data (17/08/2007), no espaçamento de 2,0 x 1,5 m. As mudas foram produzidas em ambiente protegido, em uma estrutura tipo arco, com $7 \times 20 \mathrm{~m}$ e pé direito de $2,5 \mathrm{~m}$, coberta com filme de polietileno transparente de $150 \mu \mathrm{m}$ de espessura e lateralmente com tela antiafídeos.

A calagem, a adubação de plantio e a adubação de cobertura da área experimental seguiram a recomendação de Raij et al. (1996) para essa cultura, sendo utilizados, no plantio, o adubo formulado 4-14-8, superfosfato simples e esterco de galinha. A irrigação utilizada no campo foi por aspersão e os tratos culturais, controle de pragas e doenças foram realizados de acordo com a necessidade da cultura. 
No dia do transplante foram avaliados, em amostras de três mudas por parcela, o número de folhas, a massa fresca e a massa seca por plântula. As mudas foram pesadas em balança com precisão de 0,001 g. Posteriormente, foram transplantadas para o campo cinco plantas por parcela, com o objetivo de avaliar a produção de frutos.

Foram realizadas dezessete colheitas de frutos no período de 05/10/2007 a 14/11/2007, sendo avaliados, em cada colheita, o número total de frutos, o número de frutos comerciais, a massa total de frutos, a massa de frutos comerciais, a porcentagem de frutos comerciais e a massa média de fruto comercial. Os frutos foram pesados em balança com precisão de $0,1 \mathrm{~g}$. Consideraram-se comerciais os frutos com cerca de $20 \mathrm{~cm}$ de comprimento, retos e sem defeitos aparentes. As características avaliadas foram analisadas considerando-se a média por planta. Para a produção de frutos, em número e massa por planta, considerou-se a soma da produção das 17 colheitas. Os dados, sem transformação, foram submetidos à análise de variância e, quando o quadrado médio de tratamentos foi significativo pelo teste $\mathrm{F}$ ( $5 \%$ de probabilidade), realizouse a análise de regressão em função da idade de transplante das mudas.

\section{RESULTADOS E DISCUSSÃO}

$\mathrm{Na}$ fase de muda não foi observada diferença significativa na massa seca da parte aérea em função da idade de transplante, com média de $0,50 \mathrm{~g}$ por planta. No entanto, houve diferença no número de folhas e na massa fresca da muda, sendo que aquelas, com 32 dias após a semeadura, apresentaram maiores valores para essas características e, acima dessa idade, tanto a massa fresca como o número de folhas diminuíram, ajustando-se a um modelo de regressão quadrática (Figura 1). Porém, as mudas transplantadas com 32 dias após a semeadura não foram as que resultaram em maior produção total por planta (Figura 2), indicando que nem sempre a muda com maior massa ou maior número de folhas é a melhor, pois depois de certa idade o desenvolvimento de seu sistema radicular pode ter sido prejudicado, afetando o desempenho posterior da planta, comparativamente às mudas transplantadas com menor idade. Se as mudas forem mantidas por período muito longo nas bandejas, pode ocorrer restrição ao desenvolvimento radicular, enovelamento de raízes e, mesmo que visualmente imperceptível, deficiência de nutrientes, com efeito sobre o desempenho da cultura. Assim, infere-se que mudas maiores não significam mudas de melhor qualidade. Lamont (1992) e Seabra Júnior et al. (2004) também observaram que nem sempre mudas com maior número de folhas e maior massa fresca, na fase de transplante, foram as que resultaram em maior produção comercial. Porém, assim como estes autores, neste trabalho percebeu-se que quanto mais velhas as mudas, melhor é a formação do torrão que se mantinha intacto, facilitando o transplante.

Pode-se observar que as massas total e de frutos comercial, bem como o número total de frutos por planta se ajustaram a um modelo de regressão quadrática em função da idade de transplante da muda (Figura 2). De acordo com a análise de regressão, estima-se que os melhores resultados para essas características são obtidos com mudas transplantadas aos 27 dias após a semeadura. Segundo Nesmith \& Duval (1998) e Pereira \& Martinez (1999), o tempo em que as mudas permanecem com seu sistema radicular restringido deve ser o mínimo possível, pois essa restrição reduz o fornecimento de nutrientes para a parte aérea. Provavelmente, as raízes de mudas mais novas não sofreram restrição, estabelecendo-se e desenvolvendo com mais facilidade.
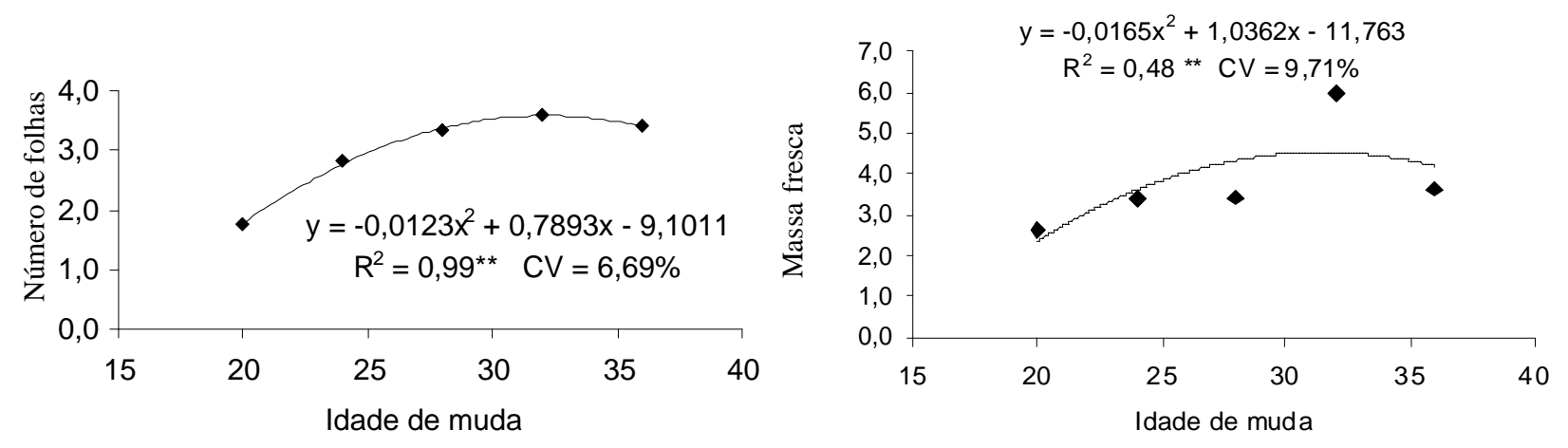

Figura 1 - Número de folhas e massa fresca da parte aérea de mudas de abobrinha híbrida Sandy, em função da sua idade de transplante. FCA/UNESP, São Manuel, SP, 2007.

(* $\mathrm{e}^{* *}$ : valores significativos a 5 ou $1 \%$ de probabilidade, respectivamente). 

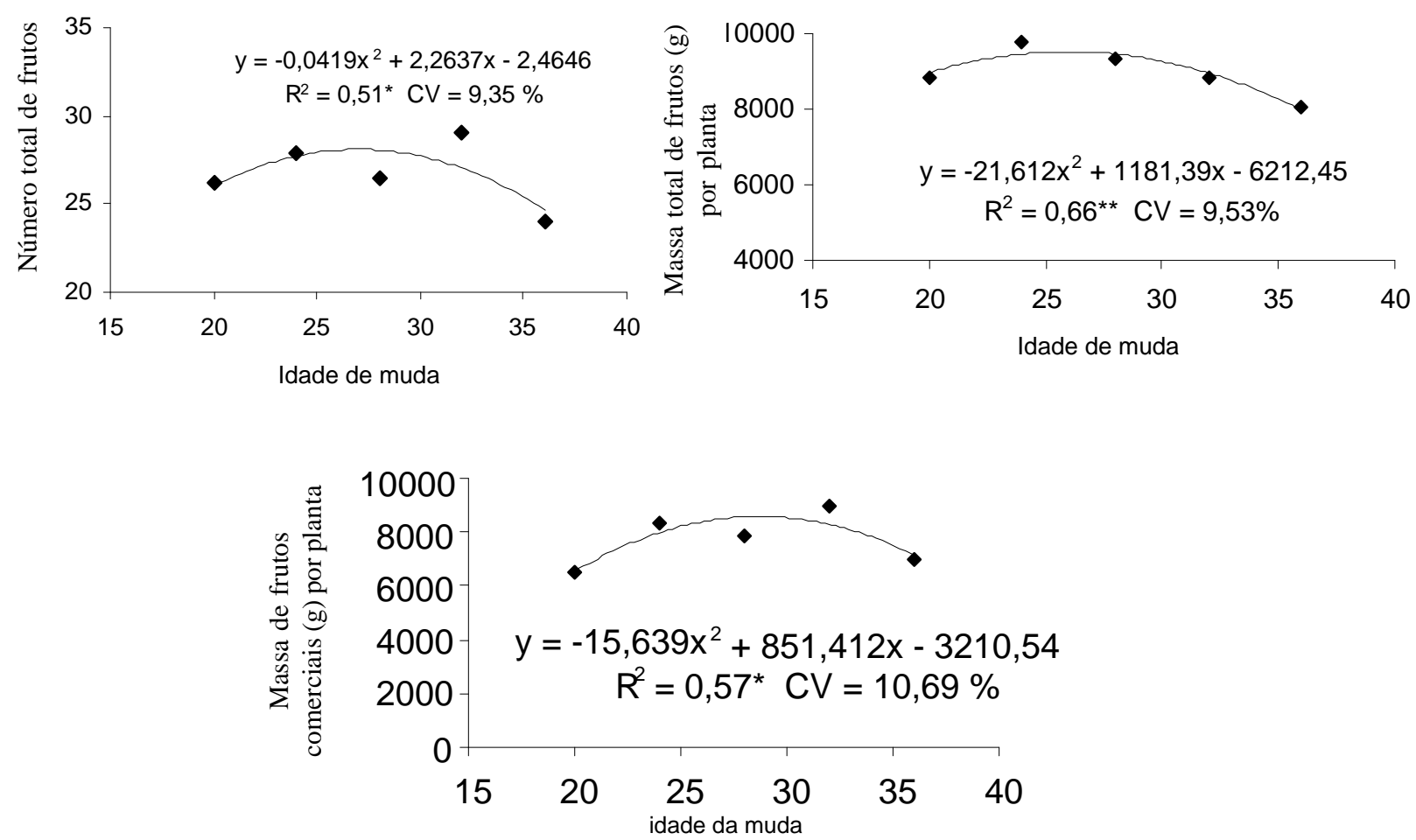

Figura 2 - Massa de frutos comerciais, massa de frutos totais e número de frutos totais por planta em função da idade da muda, em abobrinha híbrido Sandy. FCA/UNESP, São Manuel, SP, 2007.

(* $\mathrm{e}^{* *}$ : valores significativos a 5 ou $1 \%$ de probabilidade, respectivamente).

Portanto, para as condições deste experimento, mudas com cerca de quatro semanas obtiveram melhor desempenho, o que ficou pouco acima dos resultados encontrados por Seabra Júnior et al. (2004), com pepino, que recomenda a utilização de mudas com até 19 dias após a semeadura para bandejas de 128 células, semelhantes às utilizadas nesse experimento. Já para a cultura da melancia, Vavrina et al. (1993) relataram que a idade da muda não afetou a produção, sendo o mesmo observado por Kano et al. (2008) em couve-brócolo. Porém, Godoy \& Cardoso (2005) relataram que mudas muito novas ou muito velhas reduziram a produtividade da couve-flor, recomendando o transplante de mudas com 32 dias e com três a quatro folhas.

Borne (1999) recomenda o transplante das mudas de cucurbitáceas com três semanas (21 dias). Provavelmente, o motivo pelo qual, na presente pesquisa, as melhores mudas foram àquelas obtidas com 27 dias após a semeadura, seja decorrente das condições ambientais, como as temperaturas amenas (mínima de $9,7^{\circ} \mathrm{C}$, média diária de $16,9^{\circ} \mathrm{C}$ e máxima de $24,3^{\circ} \mathrm{C}$ ), o que resulta em menor velocidade de desenvolvimento. Portanto, é essencial que se relacione à idade cronológica ao estágio de desenvolvimento da planta, pois, de acordo com as condições ambientais, principalmente de temperatura, a velocidade de desenvolvimento das mudas pode variar. Assim, o número de dias pode não ser um bom parâmetro de avaliação. Já, o número de folhas é mais confiável para descrever o momento ideal de transplante das mudas, pois pode ser facilmente reproduzido e determinado em quaisquer condições do ambiente (Seabra Júnior et al., 2004). Desse modo, de acordo com a regressão ajustada (Figura 1), estima-se que mudas com 27 dias apresentam, nas condições desse experimento, aproximadamente 3,2 folhas, sendo este o número ideal para se realizar o transplante. Porém, a idade da muda não influenciou o número de frutos comerciais por planta, a porcentagem de frutos comerciais e massa média de frutos comerciais, que apresentaram médias gerais de 22,3 frutos por planta, $83,6 \%$ e 353 g por fruto, respectivamente. Apesar da ausência de diferenciação significativa $(p>0,05)$ para o número e a porcentagem de frutos comerciais, foi obtida diferença significativa $(\mathrm{p}<0,05)$ para a massa de frutos comerciais por planta, o que justifica concluir que mudas 
com 3,2 folhas (27 dias) foram as de melhor desempenho, pois a comercialização dos frutos é feita em massa de frutos.

Em estudos sobre produção de mudas, a avaliação do desenvolvimento após o transplante é de fundamental importância, visto que, nem sempre uma muda avaliada como excelente no momento do transplante é a que resultará em maior potencial produtivo, como se verificou no presente trabalho. Conforme relatado por Belfort \& Gomes (2000), a idade avançada em que as mudas vêm sendo transplantadas pode prejudicar a sua qualidade, com redução do desenvolvimento e da produção. Portanto, mudas mais velhas, com a parte aérea mais desenvolvida, que são as preferidas por alguns produtores, por apresentarem sistema radicular compacto e maior facilidade para serem transplantadas, podem reduzir a produtividade da abobrinha.

\section{CONCLUSÕES}

A maior produção de frutos de abobrinha por planta foi obtida com mudas que apresentavam 3,2 folhas, o que correspondeu às mudas transplantadas aos 27 dias após semeadura.

\section{AGRADECIMENTOS}

À Capes e Fapesp pela concessão de bolsas.

\section{REFERÊNCIAS BIBLIOGRÁFICAS}

BELFORT, C.C.; GOMES, M.S.F.D. Avaliação da idade de transplantio para mudas de melancia. Horticultura Brasileira, Brasília, v.18, p.468-469, jul. 2000.

BORNE, H.R. Produção de mudas de hortaliças. Guaíba: Agropecuária, 1999. 187p.

CUNHA, A.R.; MARTINS, D. Classificação climática para os municípios de Botucatu e São Manuel, SP. Botucatu: UNESP, 2008.

EMPRESA BRASILEIRA DE PESQUISA AGROPECUÁRIA. Sistema brasileiro de classificação de solos. Brasília: Embrapa. 1999. 412p.

FILGUEIRA, F.A.R Brassicáceas: couves e plantas relacionadas In: FILGUEIRA, F.A.R. Novo manual de olericultura: agrotecnologia moderna na produção e comercialização de hortaliças. Viçosa, MG: UFV. 2003. p.275-294.

GODOY, M.C.; CARDOSO, A.I.I. Produtividade da couve-flor em função da idade de transplantio das mudas e tamanhos de células na bandeja. Horticultura Brasileira, Brasília, v.23, n.3, p.837-840, jul./set. 2005.
KANO, C.; GODOY, A.R.; HIGUTI, A.R.O.; CASTRO, M.M.; CARDOSO, A.I.I. Produção de couve-brócolo em função do tipo de bandeja e idade das mudas. Ciência e Agrotecnologia, v.33, n.1, p.110-114, 2008.

LAMONT, W.J. Transplant age has little effect on broccoli head weight and diameter. Horticultural Science, Alexandria, v.27, n.7, p.848, 1992.

LESKOVAR, D.I.; CANTLIFFE, D.J.; STOFFELLA, P.J. Growth and yield of tomato plants in response to age of transplants. Journal of the American Society for Horticultural Science, Alexandria, v.116, n.3, p.416-420, 1991.

MINAMI, K. Mudas hortícolas de alta qualidade. In: . Produção de mudas de alta qualidade em horticultura. São Paulo: T.A. Queiroz, 1995. p.19-27.

NESMITH, D.S. Transplant age influences summer squash growth and yield. Horticultural Science, Alexandria, v.28, p.618-620, 1993.

NESMITH, D.S.; DUVAL, J.R. The effect of container size. Horticultural Technology, Alexandria, v.8, n.4, p.495-498, 1998.

PEREIRA, P.R.G.; MARTINEZ, H.E.P. Produção de mudas para o cultivo de hortaliças em solo e hidroponia. Informe Agropecuário, Belo Horizonte, v.20, n.200/201, p.24-31, 1999.

RAIJ, B. van; CANTARELLA, H.; QUAGGIO, J.A.; FURLANI, A.M.C. Recomendações de adubação e calagem para o Estado de São Paulo. 2.ed. Campinas: Instituto Agronômico \& Fundação IAC, 1996. 285p.

SEABRA JÚNIOR, S.; GADUM, J.; CARDOSO, I.I. Produção de pepino em função da idade das mudas produzidas em recipientes com diferentes volumes de substrato. Horticultura Brasileira, Brasília, v.22, n.3, p.610-613, jul./set. 2004.

VAVRINA, C.S.; OLSON, S.; CORNELL, J.A. Watermelon transplant age: influence on fruit yield. Horticultural Science, Alexandria, v.28, p.789-790, 1993.

WESTON, L.A. Effect of flat cell size, transplant age, and production site on growth and yield of pepper transplants. Horticultural Science, Alexandria, v.23, p.709-711, 1988. 